\title{
Reproductive Aspects in Spinal Cord Injured Males
}

\author{
G. Beretta, MD, E. Chelo, MD, A. Zanollo, MD
}

Unità Socio Sanitaria Locale 72, Regione Lombardia, Ospedale di Magental Milano, Divisione Urologica, Unità di Andrologia, Sezione Mielolesi a rischio urologico della Unità Spinale Integrata, 20013 Magenta, Milano, Italy.

\section{Summary}

Infertility in paraplegic males is determined by two major factors: (1) most patients with spinal cord lesions cannot ejaculate, and (2) if ejaculation is possible, then the features of the semen are constantly abnormal. Various methods have been proposed to stimulate the ejaculatory reflex in paraplegics. From 1983 we have used for this purpose a simple vibrator applied to the penis and with this method the ejaculatory response was obtained in 72 of 102 patients treated.

Fifteen patients who desired a child, received instruction in self-using the vibrator at home weekly.

Sperm characteristics were evaluated (mean of two samples) before and after 3 months of self-use of the vibrator. Statistical evaluation of the results was performed with Student t-test. At the end of the treatment an improvement of sperm concentration and progressive motility was evident, but the result of highest statistical significance was the decrease of abnormal sperm morphology. Three couples obtained a pregnancy with $A I H$.

Key words: Infertility; Spinal cord injuries; Seminal parameters.

Handicap has been described as a condition in which physical disability is accompanied by social disadvantage. Indeed, this statement also applies to the reproductive and sexual-genital problems of paraplegics.

As long as neurophysiological investigations have overlooked this subject, the reproductive ability of patients with spinal cord lesions has been regarded as extinct or strongly impaired.

Infertility in paraplegic males is determined by two major factors: (1) most patients with spinal lesions cannot ejaculate and (2) if ejaculation is possible then the features of the semen are constantly abnormal. 
A number of methods have been suggested in order to elicit the ejaculation reflex. In 1949 Guttmann reported that intrathecally administered neostigmine succeeded in eliciting erection and ejaculation in $60 \%$ of this patients with complete upper motor neuron paralysis, and in $75^{\circ}$ o of patients with incomplete lesions. Furthermore he reported that fatherhood was made possible in 2 cases by artificial insemination. Anyway, Guttmann's method has several drawbacks: it is an invasive procedure, not easily repeatable, which has to be carried out in a hospital environment and is accompanied by severe side-effects.

Electrostimulation, widely employed in veterinary medicine, has also been tried with paraplegic patients. An electrical stimulator was inserted through the anus and applied to the prostate and seminal vesicles. Ejaculation was obtained by Francois in 1979 in 63 of his 116 patients and by Brindley (1981) in 50 of his 84 patients. Recently Halstead (1987) obtained anterograde ejaculation in 9 of 12 selected subjects with a rectal probe. This latter technique suffers from the same disadvantages of the former one. Besides, it is usually less effective (ejaculation is often retrograde) and cannot obviously be proposed for routine use. Chapelle in 1983 reported his experience in the treatment of anejaculation in 8 patients of 20 treated. Francois (1980) and Brindley (1981) reported good results using a vibrator which had been directly applied to the penis, thus triggering the ejaculation reflex. Once sperm is obtained, the ejaculate should obviously be examined to evaluate if artificial insemination is feasible. The quality of the sperm is usually poor; indeed recurrent urinary tract infections, scrotal hyperthermia (Brindley, 1982), neurogenic disorders (Bors, 1950), as well as prolonged stasis, may all result in determining seminal alterations. The present paper reports the results of a 3-year study carried out at the Center for Genital and Sexual Counselling of the Andrology Department in the General Hospital of Magenta.

\section{Materials and methods}

One hundred and two men with spinal lesions attended our sexual and genital rehabilitation program. The mean age was $25 \cdot 6$ years and the mean time interval between the traumatic event and treatment was $6 \cdot 1$ years. In 58 patients the neurological level of the lesion was above T11, 36 subjects suffered from thoracolumbar lesions and 8 from sacral lesions. Forty five patients presented with complete lesions and 57 with incomplete transection of the spinal cord. Patients were preferentially admitted to the rehabilitation program if the following requirements were satisfied:

1. No secondary neurological sequelae.

2. Empty and not irritated rectum and bladder.

3. Negative urine cultures.

4. The T12, L1 and L2 myelomeres must be intact.

Ejaculation was elicited employing a vibrator $(30 \mathrm{~W}, 220 \mathrm{~V}, 100$ vibrations/ second) applied to the penile surface for about 10 minutes (Le Vibrion, P. M. Jeuilly, 15 Rue De Gaulle, 42000 St Etienne, France).

Patients who desired fecundation of their partners were instructed to use the vibrator at home. Weekly simultation over 3 months was advised.

A follow-up study of the main seminal parameters (concentration, volume, 
Table Characteristics of subjects and results of vibromassage

\begin{tabular}{|c|c|c|c|c|}
\hline $\begin{array}{l}\text { Neurological level } \\
\text { of the lesion }\end{array}$ & $\begin{array}{l}\text { No. of } \\
\text { cases }\end{array}$ & Type of lesion & Ejaculation & Side-effects \\
\hline \multirow[t]{2}{*}{ Cervical } & 17 & 7 complete & 7 & $\begin{array}{c}1 \text { headache/raised arterial } \\
\text { blood pressure }\end{array}$ \\
\hline & & 10 incomplete & 8 & - \\
\hline \multirow[t]{2}{*}{$\mathrm{T} 1-\mathrm{T} 10$} & 41 & 22 complete & 20 (1 retrograde: $\mathrm{D} 7)$ & $\begin{array}{c}1 \text { headache/raised arterial } \\
\text { blood pressure }\end{array}$ \\
\hline & & 19 incomplete & $\begin{array}{l}15 \text { (1 dripping: D5-D6, } \\
1 \text { retrograde: D8-D9) }\end{array}$ & - \\
\hline \multirow[t]{2}{*}{$\mathrm{T} 11-\mathrm{L} 1$} & 21 & 10 complete & 3 (1 dripping) & - \\
\hline & & 11 incomplete & $\begin{array}{l}9 \text { ( } 2 \text { dripping, } \\
3 \text { retrograde })\end{array}$ & - \\
\hline \multirow[t]{2}{*}{ L2-L5 } & 15 & 3 complete & - & 一 \\
\hline & & 12 incomplete & $\begin{array}{c}7 \text { (4 dripping: } \\
\text { L2; L2; L2-L 3; L4) } \\
\text { (2 retrograde: } \\
\text { L2-L3; L5) }\end{array}$ & - \\
\hline \multirow[t]{2}{*}{ Sacral } & 8 & 3 complete & - & - \\
\hline & & 5 incomplete & 3 (3 dripping) & \\
\hline
\end{tabular}

motility and morphology) was carried out. The mean values of each parameter from two samples were calculated before and after treatment (weekly stimulation at home). The two means were compared using Student's t-test.

If the quality of the sperm was good, the female partners of our patients underwent fertility investigations, such as hysterosalpingography, progesterone and prolactine assays in the second phase of the menstrual cycle and cervical mucus score determination.

Homologous intracervical insemination was then performed during ovulation.

\section{Results}

The use of penile vibrators triggered ejaculation in 72 patients $(70.5 \%)$. Retrograde ejaculation occurred in 7 patients; 11 more patients showed 'weak' ejaculation due to feeble contractions of perineal muscles, with 'dripping' of the semen on emission (Table).

Sixty seven of 72 patients who responded positively to the application of vibrators experienced their first ejaculation since the trauma had occurred.

The response took place after a stimulation period ranging from 30 seconds to 20 minutes.

Only 2 patients showed unpleasant side-effects, consisting of headache and raised arterial blood pressure upon ejaculation.

Fifteen patients attended the program of weekly stimulation at home. Seminal parameters varied as follows: statistically significant increase in sperm concentration $(\mathrm{p}<0.05)$ was not accompanied by a comparable increase in volume (Fig. 1 and Fig. 2). The most significant positive modifications regarded motility 


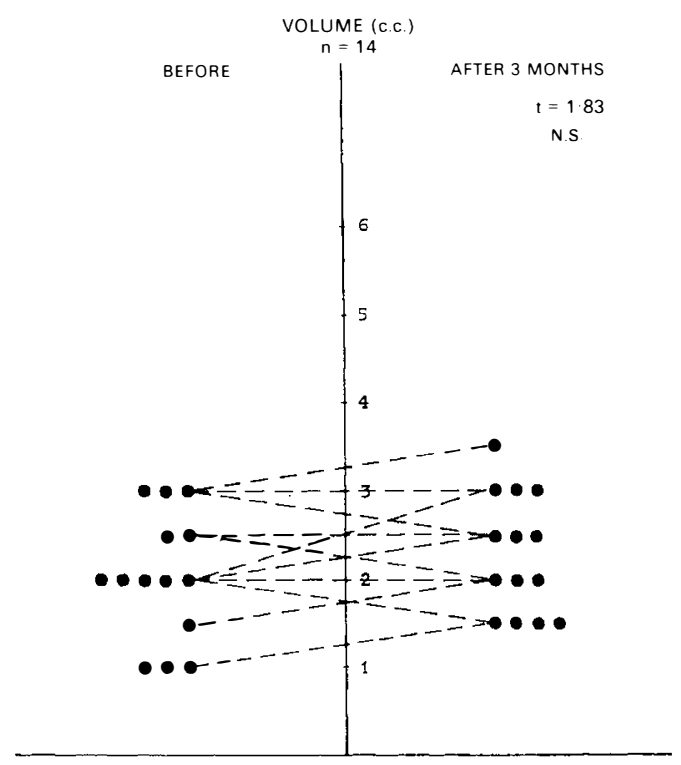

Figure 1 Seminal volume.

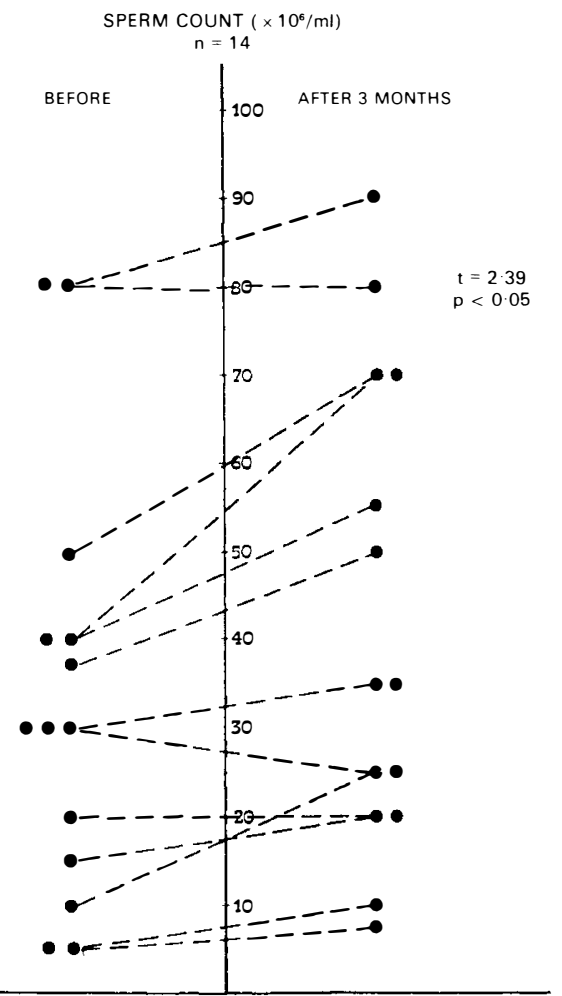

Figure 2 Seminal sperm count. 


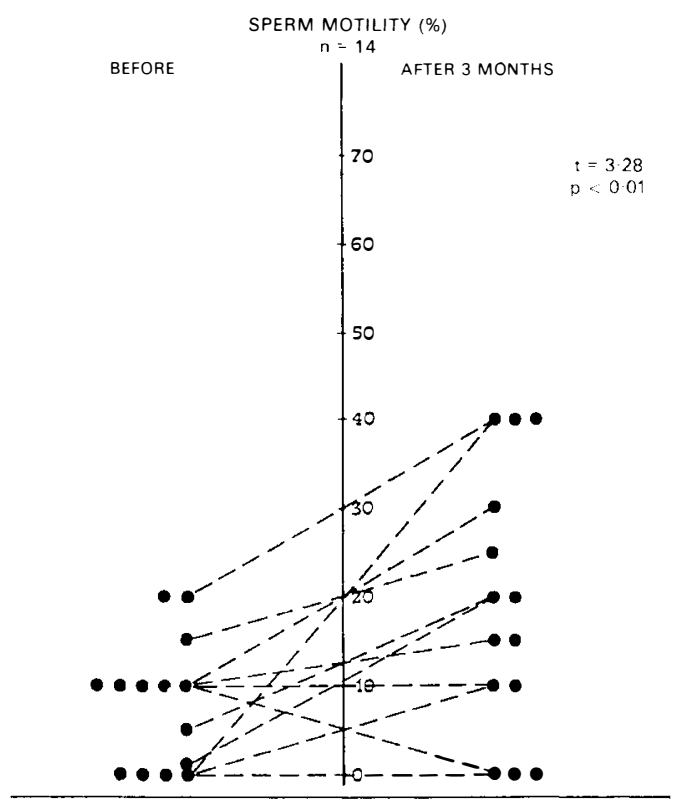

Figure 3 Sperm motility.

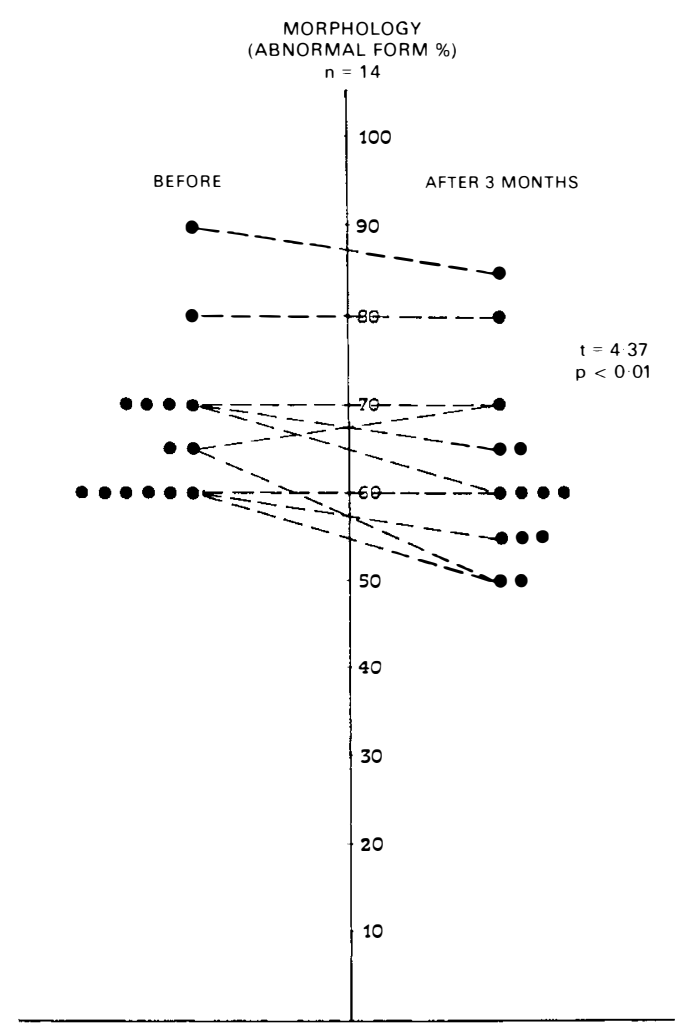

Figure 4 Sperm morphology. 
and morphological features: abnormal spermatozoa steeply decreased over 3 months $(\mathrm{p}<0.01)$ (Fig. 3 and Fig. 4).

Six couples underwent homologous insemination (AIH), and 1 couple of these asked to be trained for self-insemination at home.

Until now, 3 female partners have become pregnant, 2 of them at the first and 1 at the second cycle of AIH.

\section{Conclusions}

The use of penile vibrators yielded remarkably positive results: vibrators are highly successful in eliciting ejaculation and they are simple and safe enough to be employed at home after a short training; furthermore, these devices are virtually devoid of unpleasant side-effects.

Although no conclusive explanation has yet been given as to the poor quality of sperm from paraplegic patients, our experience seems to confirm that prolonged use of vibrators results in improved seminal quality.

Our results are in agreement with data reported by Brindley (1984) who demonstrated evidence of an improvement in sperm quality, though he did not find any significant variation in volume; he also stressed that the proportions of retrograde ejaculation was very low.

Finally, we wish to emphasise that for the first time in Italy the partners of paraplegic males were fecundated: this event opens new perspectives as to the quality of life of paraplegic patients.

\section{References}

Bors E, ENGLE ET, Rosenquist RC, et al. 1950 Fertility in paraplegic males: A preliminary report of endocrine studies. Fournal of Clinical Endocrinology and Metabolism 10: 381.

Bors E, COMmar AE 1960 Neurological disturbances of sexual function with special reference to 529 patients with spinal cord injury. Urologic Survey 10:191.

BRINDLEY GS 1981 Electroejaculation: its technique, neurological implication and uses. fournal of Neurosurgery and Psychiatry 44(9).

BRINDLEY GS 1981 Reflex ejaculation under vibratory stimulation in paraplegic men. Paraplegia 19:299.

BRINDLEY GS 1982 Deep scrotal temperature and the effect on it of clothing air temperature, activity, posture and paraplegia. British fournal of Urology 54:49.

BRINDLEY GS 1984 The fertility of men with spinal cord injuries. Paraplegia 22:337.

Chapelle PA, Blanquart F, Puech AJ, et al. 1983 Treatment of anejaculation in the total paraplegic by subcutaneus of physostigmine. Paraplegia 21:30.

Francois N, Maury M, Jouannet P, et al. 1979 Notre experience de l'electroejaculation chez le paraplegique. Fournal Urologie Nefrologie 85:513.

Francois N, Lichtenberger JM, Jouannet P, et al. 1980 L'ejaculation par le vibromassage chez le paraplegiaque a propose de 50 cas avec 7 grossesses. Annales de medicine Phisique 23:24.

GUTTMANN L 1949 The effect of prostigmine on the reproductive functions in the spinal man. Proceedings of the 4th International Neurological Congress Vol 2 Masson Paris page 69.

Halstead LS, VerVoort S, Seager SWJ 1987 Rectal Probe electrostimulation in the treatment of anejaculatory spinal cord injured men. Paraplegia 25:120. 